\title{
THE POSSIBILITIES OF THE TITANIUM DIOXIDE NANOPARTICLES PREPARATION AND THEIR APPLICATION TO THE PTFE COATING
}

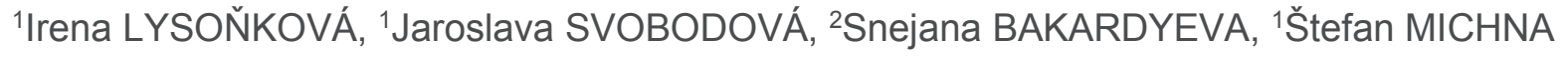 \\ ${ }^{1} \mathrm{~J}$. E. Purkyne University in Usti nad Labem, Faculty of Mechanical Engineering, Usti nad Labem, \\ Czech Republic,EU, irena.Iysonkova@ujep.cz, jaroslava.svobodova@ujep.cz, stefan.michna@ujep.cz \\ 2úJV Řež, a.s., Husinec, Czech Republic, snejana.bakardyeva@ujv.cz
}

https://doi.org/10.37904/metal.2019.736

\begin{abstract}
The technology of preparation and subsequent use of nanoparticles is currently a very actual topic, because these particles may have different properties opposite to the conventional materials from which these particles are produced. This article is focused on the production and application of titanium dioxide nanoparticles produced using different methods and their application to the PTFE matrix to create the functional composite coating. The polymorphic compound, described in this article, was chosen, because it has good catalytic properties for subsequent use. In this article, three possibilities of production of nanoparticles are presented. Each of these methods produces a specific particle shape, size, and specific morphology. This also implies the subsequent properties that these different particles have. In the article is also described the use of particles, specifically their application to a PTFE coating. The article presents the process of composite coating preparation. This composite coating is developed for application to an aluminium substrate (silumin) for a particular application in the practice. Subsequently, it was observed the uniformity of the distribution and anchoring of these particles in the coating across the sample surface. In this paper we present the results from the measurement of the coefficient of friction as a function of temperature and the measurement of the nano hardness of the coating.
\end{abstract}

Keywords: Nanoparticles, titanium dioxide, PTFE matrix, particles production, silumin, composite coating

\section{INTRODUCTION}

Nanoparticles and their applications are currently very actual. Opportunities and possibilities for their use are almost all sectors because the particles of this size bring new features unlike particles in micro-size and larger. This paper deals with the preparation of nanoparticles and nanocoatings in various ways.

The possibilities of preparing nanoparticles and nanocoatings are described, for example, by Namita Rajput in Methods of Preparation of Nanoparticles - A Review and by Konwar Rajnit et al. in Nanoparticle: An Overview of Preparation, Characterization, and Application. These articles describe methods of nanomaterial synthesis (gas condensation, vacuum deposition, and vaporization, chemical vapor deposition (CVD) and chemical vapour condensation ( $C V C$ ), mechanical, chemical precipitation, sol-gel techniques, electrodeposition), the types of nanoparticles, characterization and methods for nanoparticles studying. [1,2]

There are different approaches to the classification of nanomaterials. Nanoparticles are classified according to $0 \mathrm{D}, 1 \mathrm{D}, 2 \mathrm{D}, 3 \mathrm{D}$ objects. Preparation of particles according to their growth possibilities in different directions and specific examples are described in the article Nanoparticle: An Overview of Preparation, Characterization by Konvar Ranjit et al. [3] The preparation of nanoparticles depends on the material from which they are made - preparation of nanoparticles from metal, polymer nanoparticles or preparation of nanoparticles from metal oxides; what should be the final size of the parts; what are the properties of the particles (stability and solubility in water); surface charge and throughput, etc. Methods for preparing nanoparticles can be classified by different approaches. One of them is the preparation by Bottom-up, chemical Reaction, Top-down or combinations of these approaches. Nanoparticle preparation procedures are described e.g. in sources. $[4,5,6]$ 


\section{EXPERIMENT - PREPARATION OF NANOAPRTICLES}

\subsection{Method of nanoparticles preparation - SLS}

Using the SLS (solid-liquid-solid) method, nanoparticles were formed in the form of sticks. In super cooled solution is added ammonia and thus results in polycrystals - 1D object titanium dioxide (Figure 1). At preparing nano sticks was in the mixture of $100 \mathrm{ml}$ demi water and $50 \mathrm{ml}$ ice added $4.8 \mathrm{~g}$ titanyl sulphate. This mixture was a few hours stirred to attainment on room temperature. The beaker was subsequently shut down until the particles settled on the bottom of the vessel. Subsequently, the solution was decanted. This decantation procedure was repeated three times, each time after $350 \mathrm{ml}$ of water was added and 10 minutes of stirring, to completely replace the sulphate ions dissociated from $\mathrm{TiOSO}_{4}$ with the hydroxyl anions. After the last decantation, the powder on the filter paper was dried and then stored. [8]
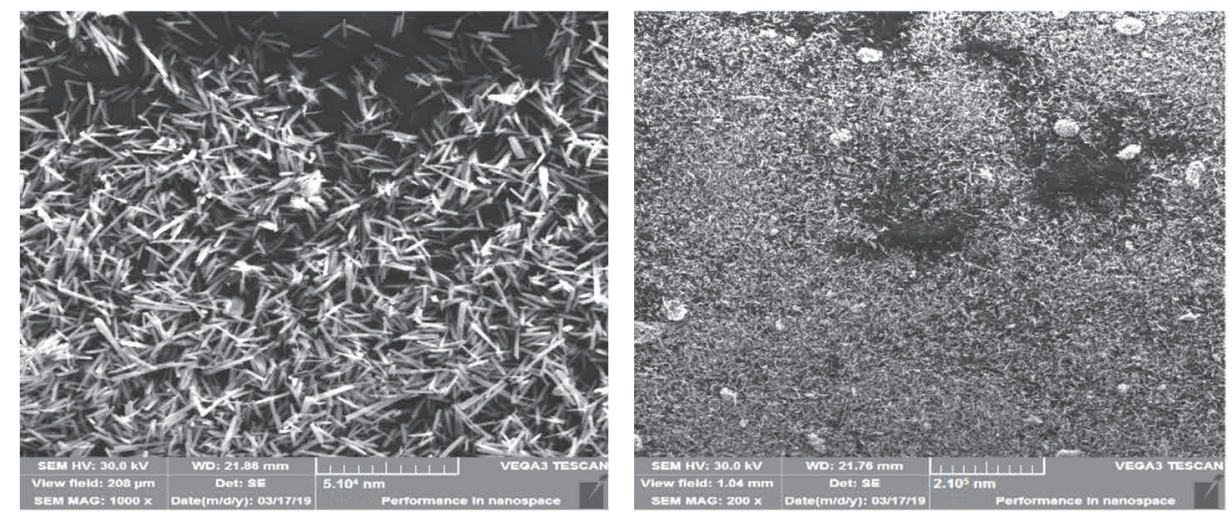

Figure 1 Titanium dioxide nanoparticles prepared by SLS method

\subsection{Method of nanoparticles preparation - lyophilisation followed by annealing}

The next method in the experiment is the preparation of nano objects by chemical means, where was used lyophilisation followed by annealing to a given temperature. During preparation were first dissolved $4.8 \mathrm{~g}$ of titanyl sulfate $\left(\mathrm{TiOSO}_{4} . \mathrm{nH}_{2} \mathrm{O}\right)$ in $150 \mathrm{ml}$ water in temperature $35^{\circ} \mathrm{C}$. Thereafter was solution cooled one hour and after was added in solution (temperature $0{ }^{\circ} \mathrm{C}$ ) dropwise ammonium to $\mathrm{pH}$ 8. The precipitate was allowed to stand for one hour for $\mathrm{pH}$ stabilization and then filtered. The filtration procedure is repeated twice more, each time in $350 \mathrm{ml}$ of water. With hydrogen peroxide $(30 \%, 47 \mathrm{~mL})$, the $\mathrm{pH}$ is lowered to 2.5 . The sample was then freeze-dried at $5-10 \mathrm{mTorr}$ and $-64^{\circ} \mathrm{C}$. The samples were subsequently annealed to obtain the desired crystallographic structure. If we want to achieve anatase structure, a temperature of $450-480{ }^{\circ} \mathrm{C}$ is sufficient. Annealing at $900^{\circ} \mathrm{C}$ is required to recrystallize anatase to rutile. In Figure 2 is a mixture of anatase and rutile after annealing with temperature $950^{\circ} \mathrm{C}$. [9]

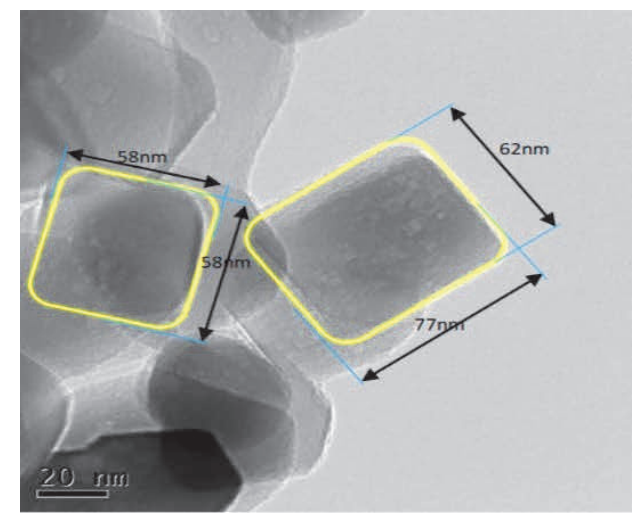

Figure 2 Titanium dioxide nanoparticles prepared by method lyophilisation followed by annealing [9] 


\section{PRACTICAL APPLICATION}

One of the possible uses of the thus formed particles is their application to the selected polymer matrix. It is the PTFE matrix in our experiment. Applying the mixture PTFE with nanoparticles on the aluminium substrate creates a composite coating of the specific properties. The basic material (substrate) is AISi9Mg0.3Mn0.1. The composite coating is prepared with the use of following steps: alkaline degreasing (bath of the 1 I volume, application temperature $50^{\circ}, \mathrm{pH} 10-11.5$, application time $2 \mathrm{~min}$ ), zirconium passivation (bath of the 1 I volume, room temperature, $\mathrm{pH} 4.8$ - 5.2, application time $3 \mathrm{~min}$ ). After application of the zirconium passivation, the samples were dried in an oven at $115^{\circ} \mathrm{C}$ for $15 \mathrm{~min}$. Among the various process steps for chemical surface treatment, the samples were rinsed in demineralised water (DEMI water, $\mathrm{pH} 5-7$ ). The final coating is a liquid state PTFE matrix into which nanoparticles have been admixed (with stirring, application temperature $65{ }^{\circ} \mathrm{C}$, $\mathrm{pH} 7.5-8.5$, application time $15 \mathrm{~min}$ ). After application, the composite coating is dried in an oven at $100{ }^{\circ} \mathrm{C}$ for $30 \mathrm{~min}$. For all chemical preparations, the application technology is Dip coating. Nanostructured titanium dioxide $\left(\mathrm{TiO}_{2}\right)$ micro-sticks with a length of $8-11 \mu \mathrm{m}$ and a diameter of $5-10 \mathrm{~nm}$ were used as a filler of the PTFE matrix. These sticks were prepared from hydrated crystals of titanyl sulfate $\left(\mathrm{TiOSO}_{4} * \mathrm{H}_{2} \mathrm{O}\right)$. Concentration of the sticks were chosen $0.1 \%, 0.01 \%$ and $0.001 \%$ in the PTFE solution ( $\%$ relative to the total volume of the coating bath). Figure $3 \mathrm{~A}$ documents composite coating, where titanium dioxide particles were used in the form of sticks. It is apparent from the figure documentation that the deposited coating is homogeneous and the parts in the matrix are evenly dispersed. An important parameter for the practical application of this type of coating is also its thickness. The thickness is between 10 and $30 \mu \mathrm{m}$ (Figure 3B).
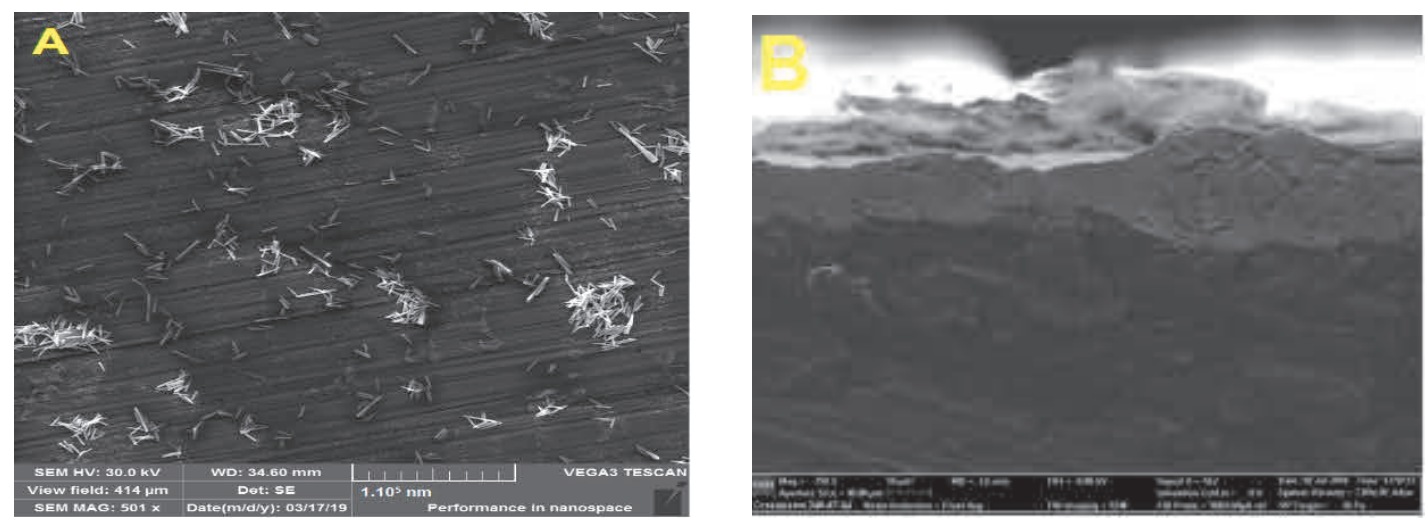

Figure 3 Composite coating PTFE matrix $+\mathrm{TiO}_{2}$ sticks and the thickness of the composite coating

The coating is in the testing phase. At this moment we can give results from the evaluation of the dependence of the coefficient of friction on the thermal load of the coating. The composite coating was loaded at temperatures from 150 to $500^{\circ} \mathrm{C}$ for $60 \mathrm{~min}$. Except the friction coefficient were measured the nano hardness of the coating.

The friction coefficient was measured on a Bruker UMT TriboLab, an indenter ball of diameter $12.7 \mathrm{~mm}, 10$ $\mathrm{mm}$ indenter track, $4 \mathrm{~N}$ load (from $300^{\circ} \mathrm{C}$ thermal load reduced to $2 \mathrm{~N}$ due to the coating degradation according to the thermal loading). When comparing the coefficient of friction of the base material and the material with the coating, it was shown that with the applied coating (PTFE or PTFE $+\mathrm{TiO}_{2}$ ) the coefficient of friction increases, Table 1. The coefficient of friction increases significantly with increasing temperature. The PTFE coating degraded at $350^{\circ} \mathrm{C}$, resulting in an intense increase in the coefficient of friction from this temperature. In the case of a composite coating (PTFE $\left.+\mathrm{TiO}_{2}\right)$, the trend of increasing the coefficient of friction was similar for all $\mathrm{TiO}_{2}$ concentrations. The coefficient of friction increases repeatedly with increasing temperature of thermal load, as is the case with PTFE coating. From the temperature of $300^{\circ} \mathrm{C}$, there was an intense increase in the coefficient, Table 2. Figure 4 shows a record of COF measurements of a PTFE $+\mathrm{TiO}_{2}$ composite coating sample (concentration $0.01 \%$ ). 
Table 1 Average values of coefficient of friction without thermal loading

\begin{tabular}{|c|c|c|}
\hline Sample & $\begin{array}{c}\text { Average COF* value (of } 10 \text { measurements } \\
\text { per sample, 5 samples) }\end{array}$ & Measurement conditions \\
\hline Basic material (no coating) & 0.148 & $\begin{array}{c}\text { Indenter - ball } \varnothing 12.7 \mathrm{~mm} ; \\
\text { indenter track }-10 \mathrm{~mm} ; \text { load }-4 \mathrm{~N}\end{array}$ \\
\hline Basic material + PTFE & 0.101 & \\
\hline Basic material + PTFE+TiO 2 & 0.100 & \\
\hline
\end{tabular}

${ }^{*}$ COF - Coefficient Of Friction

Table 2 Average values of coefficient of friction after thermal loading

\begin{tabular}{|c|c|c|c|c|c|c|c|c|c|}
\hline$\frac{0}{\frac{0}{0}}$ & 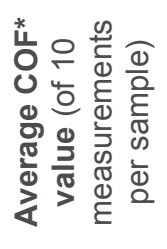 & 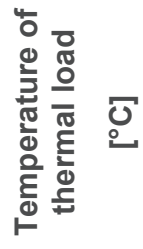 & $\stackrel{\varrho}{\stackrel{\Xi}{E}}$ & 윰 & $\frac{\frac{0}{0}}{\frac{E}{E}}$ & 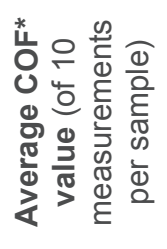 & 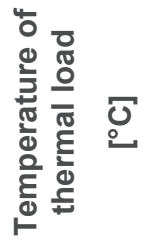 & 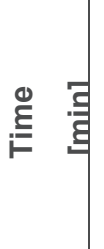 & 윰 \\
\hline $\begin{array}{c}1 \mathrm{~A} \\
\text { (PTFE } \\
\text { coating) }\end{array}$ & 0.102 & 150 & \multirow{7}{*}{60} & 4 & $\begin{array}{c}1 \mathrm{~B} \\
(\mathrm{PTFE}+ \\
\left.\mathrm{TiO}_{2}\right)\end{array}$ & 0.115 & 150 & \multirow{7}{*}{60} & 4 \\
\hline $2 \mathrm{~A}$ & 0.119 & 200 & & 4 & $2 B$ & 0.201 & 200 & & 4 \\
\hline $3 A$ & 0.184 & 250 & & 4 & $3 B$ & 0.179 & 250 & & 4 \\
\hline $4 \mathrm{~A}$ & 0.435 & 300 & & 2 & 4B & 1.297 & 300 & & 2 \\
\hline $5 \mathrm{~A}$ & 0.838 & 350 & & 2 & $5 B$ & 1.879 & 350 & & 2 \\
\hline $6 \mathrm{~A}$ & 1.335 & 400 & & 2 & $6 \mathrm{~B}$ & 1.134 & 400 & & 2 \\
\hline $7 \mathrm{~A}$ & 1.118 & 500 & & 2 & 7B & 1.182 & 500 & & 2 \\
\hline
\end{tabular}

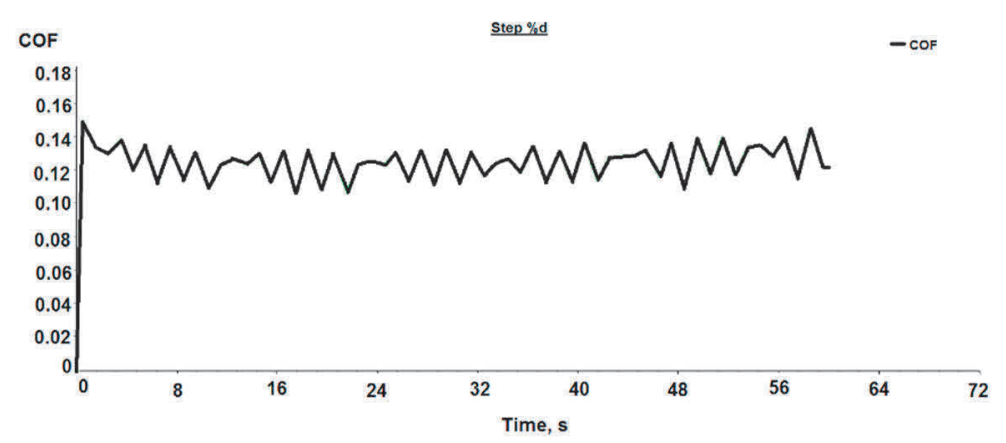

Figure 4 Graphical representation of the coefficient of friction for the sample PTFE $+\mathrm{TiO}_{2}\left(0.01 \%, 250{ }^{\circ} \mathrm{C}\right.$ thermal load, $60 \mathrm{~min}$ )

The method we used for hardness measurement of our samples was the nano indentation hardness test. The values for the nano indentation test were measured using an incisions matrix, taking several incisions at once. It was measured under the following conditions: the incisions matrix was set to $10 \times 10$ incisions, the incisions gap was $35 \mu \mathrm{m}$; the maximum load was $5 \mathrm{mN}$ and the Berkovich type indenter was used (the load according to the coating thickness).

The first measurements were performed on a basic polished material (Al-Si alloy) and a basic material with PTFE coating. With these experiments, the hardness values of the base material and PTFE were obtained. The data obtained serve to compare the hardness values on the other samples with the composite coating PTFE with $\mathrm{TiO}_{2}$ particles at different concentrations. In the Table 3, the average values are shown of the 
measured nano hardness and the standard deviation. Figure 5 shows the record from the nano hardness measurement (as an example PTFE $+0.1 \% \mathrm{TiO}_{2}$ ).

Table 3 Average values of nanohardness and standard deviation of experimental samples

\begin{tabular}{|c|c|c|c|c|}
\hline \multicolumn{5}{|c|}{ AVERAGE VALUE [GPa] } \\
\hline Basic material (Al-Si) & A (PTFE) & 1B $0.1 \% \mathrm{TiO}_{2}$ & 2B $0.01 \% \mathrm{TiO}_{2}$ & 3B $0.001 \% \mathrm{TiO}_{2}$ \\
\hline 1.02986 & 1.51688 & 2.82139 & 1.57177 & 1.46625 \\
\hline \multicolumn{5}{|c|}{ STANDARD DEVIATION [GPa] } \\
\hline Basic material & A (PTFE) & 1B $0.1 \% \mathrm{TiO}_{2}$ & 2B $0.01 \% \mathrm{TiO}_{2}$ & 3B $0.001 \% \mathrm{TiO}_{2}$ \\
\hline 0.54956 & 1.19876 & 4.83942 & 1.52201 & 4.53413 \\
\hline
\end{tabular}

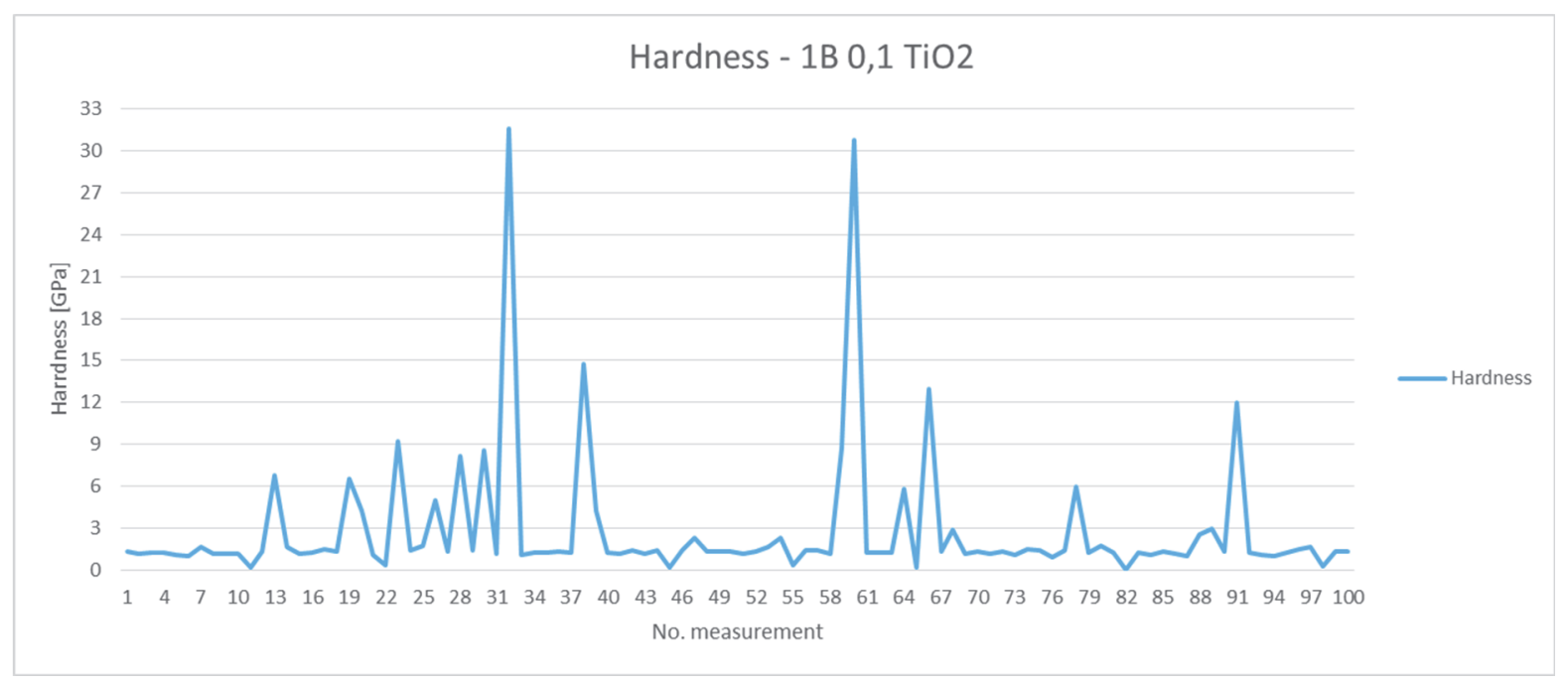

Figure 5 Nanohardness measurement of the PTFE matrix - filler $\mathrm{TiO}_{2}$ sticks ( $0.1 \%$ concentration)

The measured hardness values are moving in a different range. This measurement also heavily depended on whether the incision was performed in a particle cluster or at a site with a lower particle concentration. In the case of nanometre measurements, the highest hardness value was measured for sample 1B - PTFE $+\mathrm{TiO}_{2}$ $0.1 \%$. In the case of a sample with the lowest particle concentration, the hardness value is the lowest. The measurement is burdened by a relatively large standard deviation. It is due to the thickness of the coating and irregular distribution of particles on some samples, mainly with a lower concentration of particles. The measurement shows that the PTFE coating itself increases the hardness of the material and the addition of $\mathrm{TiO}_{2}$ nanoparticles can be beneficial in the form of an increase in the coating resistance, respectively its hardness.

\section{CONCLUSION}

This paper is devoted to various methods of preparation of nanoparticles and their applications in the form of composite coating deposited on aluminium substrate.

Introduction of the article is devoted to the classification of nano objects and methods of their production. There are possibilities of preparation of nanoparticles and nano powders. The experimental part of the paper is focused on three methods of preparation of nanoparticles and demonstration of a particular application.

- The first method of nanoparticle preparation is the SLS method. In this method, nanoparticles in the form of sticks are obtained under given conditions. The advantage of this method is the achievement of 
particle size in the nanoscale, but the disadvantage is that only a relatively small amount of particles can be obtained by this process.

- The second method of preparation is lyophilisation followed by annealing. The annealing temperature affects the resulting particle structure. The disadvantage of this method is the time of production, in a relatively long time we get a small number of particles.

- At the end of the article briefly describe application and possible use of nanoparticles in the creation of composite coating, which is composed of PTFE matrix and $\mathrm{TiO}_{2}$ and is applied to the Al substrate. With this technology, we obtained a relatively homogeneous coating. The particles are evenly distributed in the coating and a uniform layer is formed on the surface of the material. The properties of the $\mathrm{TiO}_{2}+$ PTFE composite coating are the subject of further research, as well as applications for practical applications. In this paper, we present the results from the measurement of the friction coefficient as a function of temperature and the measurement of the nano hardness of the coating. From the measurements, we can conclude that the coefficient of friction increases significantly with increasing temperature of both PTFE and PTFE $+\mathrm{TiO}_{2}$ coatings. The highest hardness was achieved with a PTFE $+\mathrm{TiO}_{2}$ composite coating with a concentration of $0.1 \%$ (2.82139 GPa). Comparing the value of PTFE without nanoparticles $(1.5168 \mathrm{GPa})$ with this nanoparticle coating, it can be stated that the particles affect increasing the hardness of the coating at a given concentration of $0.1 \% \mathrm{TiO}_{2}$.

\section{ACKNOWLEDGEMENTS}

\section{Supported by the OP VVV Project Development of new nano and micro coatings on the surface of selected metallic materials - NANOTECH ITI II., Reg. No CZ.02.1.01/0.0/0.0/18_069/0010045.}

\section{REFERENCES}

[1] RAJPUT, N. Methods of Preparation of Nanoparticles. International Journal of Advances in Engineerng \& Technology, 2015, pp. 1806-1811.

[2] RAJNIT, K. and BAQUEE, A. A. Nanoparticle: An Overview of Preparation, Characterization and Application. International Journal od Pharmacy, 2013, pp. 47-57.

[3] PAL, S. L. and JANA, P. and MANNA, P. K. and MOHANTA, G. P. and MANAVALAN, R. Nanoparticle: An overview of preparation and characterazation. Journal of Applied Pharmaceutical Science, 2011, pp. 228-234.

[4] PLIŽINGROVÁ, E. and VOLFOVÁ, L. and SVORA, P. and LABHSETWAR, N. K. and KLEMENTOVÁ, M. and SZATMÁRY, L and ŠUBRT, J. Highly photoactive anatase foams prepared from lyophilized aqueouscolloids of peroxo-polytitanic acid. Catalysis Today, 2015, pp. 107-113.

[5] IRAVANI, S. and KORBEKANDI, H. and MIRMIHAMMADI, S. V. and ZOLFAGHARI, B. Synthesis of silver nanoparticles: chemicalm physical and biological methods. Journal of Pharmaceutical Sciences, 2014, pp. 385406.

[6] YEH, Y. and CRERAN, B. and ROTELLO, V. M. Gold Nanoparticles: Preparation, Properties, and Applications in Bionanotechnology. Nanoscale, 2012, pp. 1871-1880. 